\title{
Evaluation of Pressure Generated by Resistors From Different Positive Expiratory Pressure Devices
}

\author{
Monika Fagevik Olsén PhD RPT, Maria Carlsson MSc RPT, Erik Olsén, and \\ Elisabeth Westerdahl PhD RPT
}

\begin{abstract}
BACKGROUND: Breathing exercises with positive expiratory pressure (PEP) are used to improve pulmonary function and airway clearance. Different PEP devices are available, but there have been no studies that describe the pressure generated by different resistors. The purpose of this study was to compare pressures generated from the proprietary resistor components of 4 commercial flowdependent PEP valves with all other parameters kept constant. METHODS: Resistors from 4 flow-regulated PEP devices (Pep/Rmt system, Wellspect HealthCare; Pipe P breathing exerciser, Koo Medical Equipment; Mini-PEP, Philips Respironics [including resistors by Rüsch]; and 15-mm endo-adapter, VBM Medizintechnik) were tested randomly by a blinded tester at constant flows of 10 and $18 \mathrm{~L} / \mathrm{min}$ from an external gas system. All resistors were tested 3 times. RESULTS: Resistors with a similar diameter produced statistically significant different pressures at the same flow. The differences were smaller when the flow was $10 \mathrm{~L} / \mathrm{min}$ compared with $18 \mathrm{~L} / \mathrm{min}$. The differences were also smaller when the diameter of the resistor was increased. The pressures produced by the 4 resistors of the same size were all significantly different when measuring 1.5 - and $\mathbf{2 . 0}-\mathrm{mm}$ resistors at a flow of $10 \mathrm{~L} / \mathrm{min}$ and $2.0-\mathrm{mm}$ resistors at a flow of $18 \mathrm{~L} / \mathrm{min}(P<.001)$. There were no significant differences between any of the resistors when testing sizes of 4.5 and $5.0 \mathrm{~mm}$ at either flow. The Mini-PEP and adapter resistors gave the highest pressures. CONCLUSIONS: Pressures generated by the different proprietary resistor components of $\mathbf{4}$ commercial PEP devices were not comparable, even though the diameter of the resistors is reported to be the same. The pressures generated were significantly different, particularly when using small-diameter resistors at a high flow. Therefore, the resistors may not be interchangeable. This is important information for clinicians, particularly when considering PEP for patients who do not tolerate higher pressures. Key words: positive expiratory pressure; breathing exercises; resistance breathing. [Respir Care 2015;60(10):1418-1423. (c) 2015 Daedalus Enterprises]
\end{abstract}

\section{Introduction}

Positive expiratory pressure (PEP) is used in a variety of clinical settings to improve pulmonary function and air-

\footnotetext{
Dr Fagevik Olsén is affiliated with the Department of Gastrosurgical Research and Education, Sahlgrenska Academy, Gothenburg University, Gothenburg, Sweden. Dr Fagevik Olsén and Ms Carlsson are affiliated with the Department of Physical Therapy, Sahlgrenska University Hospital and Sahlgrenska Academy, Gothenburg University, Gothenburg, Sweden. Mr Olsén is affiliated with the Chalmers University of Technology, Gothenburg, Sweden. Dr Westerdahl is affiliated with the Department of Medical Sciences, Clinical Physiology, Uppsala University, Uppsala, Sweden, and the Faculty of Medicine and Health, Surgery, Örebro University, Örebro, Sweden.
}

way clearance in patients with a risk of pulmonary impairment. ${ }^{1-3}$ The use of PEP is standard care in many hospitals for patients with pulmonary disease or neurological disorders or those undergoing surgery, especially in the Nordic countries. ${ }^{1-3}$ PEP can be created by a patient by breathing through pursed lips, with the size of the opening and the

\footnotetext{
The authors have disclosed no conflicts of interest.

Correspondence: Monika Fagevik Olsén PhD RPT, Department of Physical and Occupational Therapy, Sahlgrenska University Hospital, SE-413 45 Gothenburg, Sweden. E-mail: monika.fagevik-olsen@vgregion.se.
}

DOI: $10.4187 /$ respcare. 03587 
expiratory flow determining the pressure, ${ }^{4,5}$ and when an expiratory pressure with an average of $5 \mathrm{~cm} \mathrm{H}_{2} \mathrm{O}$ is reached. ${ }^{6}$ An inexpensive and often-used application is the blow bottle, where resistance is created by a tube submerged in water. The water column combined with the diameter and length of the tube determines the level of pressure. ${ }^{7}$ There are also several pressure- and flowgenerated devices on the market. In pressure-regulated devices, expiration is performed against a coil, and a certain pressure must be achieved to open a valve. In flowregulated devices, resistors or holes with a small lumen diameter create the resistance. The pressure here is dependent on the size of the lumen and the patient's expiratory flow through the device.

When PEP devices are used, a resistance of $5-15 \mathrm{~cm} \mathrm{H}_{2} \mathrm{O}$ is often prescribed and used in clinical practice. ${ }^{1-3}$ In pressure-regulated devices, resistors with varying diameters are used to create the resistance. Even though the diameter of the lumen on the resistor is reported to be the same, there are other components of the design, such as the length and shape of the tube, that may affect the resistance.

In a previous study, flow-regulated PEP devices were studied at a constant flow of $3-150 \mathrm{~L} / \mathrm{min} .{ }^{8}$ With the flowdependent devices that were tested (PEP mask, Pari PEP, and System 22 PEP), pressure increased with flow, and this depended on the diameter of the lumen. The valves alone, with no connection to the resistors, also acted as resistors, giving a pressure of $0.5-2.6 \mathrm{~cm} \mathrm{H}_{2} \mathrm{O}$. The authors concluded that the actual pressure should be measured to ensure the intended pressure, regardless of resistor type used. ${ }^{8}$

Different companies manufacture resistors that are adaptable not only to their own system but also to other PEP devices, and the resistors are interchangeable. There are no studies thus far that describe the pressure during PEP treatment achieved by different resistors with the same reported lumen diameter. The purpose of this study was to compare pressures generated by the proprietary resistor components of 4 commercial flow-regulated PEP valves. Our hypothesis was that the pressures from the 4 different PEP valves would be the same when all other parameters were kept constant.

\section{Methods}

In this study, we compared resistors from 4 different flow-regulated PEP devices. The rationale for choosing these 4 PEP devices was that they are commonly used in clinical practice in Swedish hospitals. They were: the Pep/Rmt system (Wellspect HealthCare, Mölndal, Sweden), with 8 resistors with diameters of $1.5 \mathrm{~mm}$ (black), $2.0 \mathrm{~mm}$ (white), $2.5 \mathrm{~mm}$ (yellow), $3.0 \mathrm{~mm}$ (blue), $3.5 \mathrm{~mm}$ (green), $4.0 \mathrm{~mm}$ (orange), $4.5 \mathrm{~mm}$ (dark red), and $5.0 \mathrm{~mm}$

\section{QUICK LOOK}

\section{Current knowledge}

Positive expiratory pressure (PEP) is commonly employed in an attempt to improve lung function and enhance secretion removal in a variety of diagnoses. The utility of PEP has been questioned in many patients, and the evidence for routine use is scant. PEP is provided by a variety of devices using different methods to create expiratory pressure and flow resistance. The role of the device in the success of PEP has not been evaluated.

\section{What this paper contributes to our knowledge}

Pressures generated by the different proprietary resistor components of 4 commercial PEP devices were not comparable, even though the diameter of the components is reported to be the same. The pressures generated were significantly different, particularly with smalldiameter resistors at a high flow. The impact of pressure on the success of PEP therapy remains unknown.

(brown); the Pipe P breathing exerciser (Koo Medical Equipment, Hong Kong, China), with 8 resistors with diameters of $1.5 \mathrm{~mm}$ (black), $2.0 \mathrm{~mm}$ (white), $2.5 \mathrm{~mm}$ (yellow), $3.0 \mathrm{~mm}$ (blue), $3.5 \mathrm{~mm}$ (green), $4.0 \mathrm{~mm}$ (orange), $4.5 \mathrm{~mm}$ (dark red), and $5.0 \mathrm{~mm}$ (brown); the Mini-PEP (Philips Respironics, Murrysville, Pennsylvania), with 8 resistors (Rüsch, Duluth, Georgia) with diameters of 1.5, 2.0, 2.5, 3.0, 3.5, 4.0, 4.5, and $5.0 \mathrm{~mm}$ (all light blue); and the 15 -mm endo-adapter (VBM Medizintechnik, Sulz am Neckar, Germany), with 6 resistors with diameters of $2.0 \mathrm{~mm}$ (white), $2.5 \mathrm{~mm}$ (yellow), $3.0 \mathrm{~mm}$ (blue), $3.5 \mathrm{~mm}$ (green), $4.0 \mathrm{~mm}$ (orange), and $5.0 \mathrm{~mm}$ (transparent). Figure 1 shows illustrations of the resistors.

The PEP valve used for all tests was Pipe P. The external gas system of the hospital was used to achieve a constant flow. The gas was connected to the inspiratory valve. The resistor on the inspiratory valve and the valve that is normally connected to the mouthpiece or mask was plugged, and there was no air leakage in the system during testing. A manometer (range of 0-70 $\mathrm{cm} \mathrm{H}_{2} \mathrm{O}$ ) was connected to the expiratory valve with an intermediate piece. All resistors were tested at flows of 10 and $18 \mathrm{~L} / \mathrm{min}$. Each resistor was tested 3 times at each flow. All resistors were placed in a box, mixed, and randomly tested by a physiotherapist. To minimize the risk of bias, the investigator was blinded. The box and valves were covered with a cloth, and the resistors were randomly picked from the box and put into the covered valve, after which the pressure was read on the manometer. The accuracy of the readings was set to $0.5 \mathrm{~cm}$. All resistors were tested 3 times without interruption dur- 
ing each test, that is, the flow was not changed during the test.

\section{Statistics}

SPSS 15.0 (SPSS, Chicago, Illinois) was used for statistical analyses. Data are presented as mean \pm SD. Data obtained at 10 and $18 \mathrm{~L} / \mathrm{min}$ were analyzed separately. Differences between the measured pressures from the 4 resistors were analyzed by analysis of variance and the Tukey post hoc test. Statistically significant differences were set at $P<.05$.

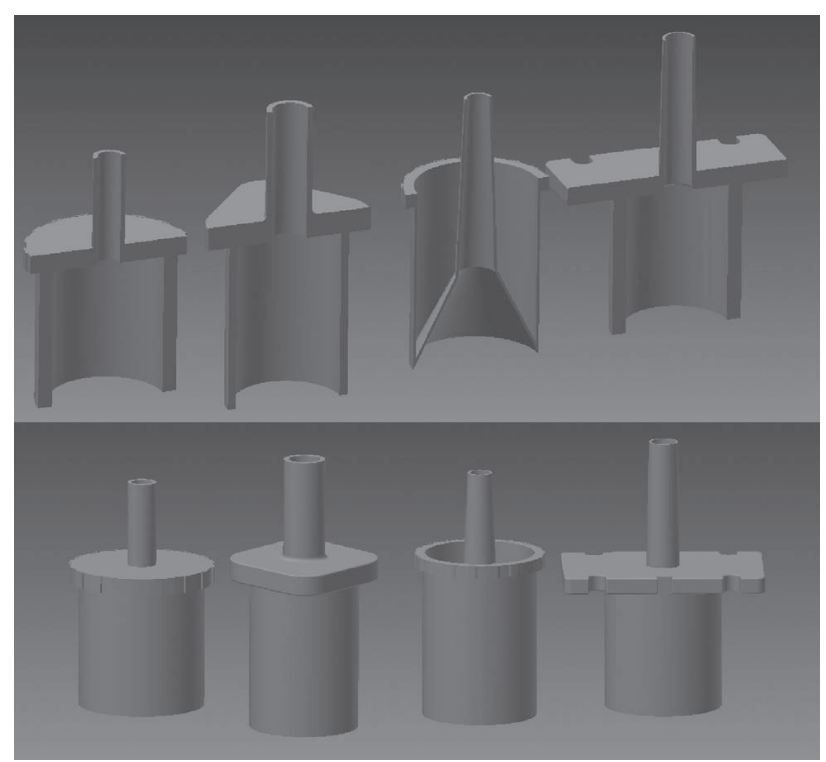

Fig. 1. Front views and cross-sections of the resistors tested. From left to right: Pep/Rmt system, Pipe P, Mini-PEP, and 15-mm endo-adapter.

\section{Results}

Pressures obtained from the tests of the different resistors at flows of 10 and $18 \mathrm{~L} / \mathrm{min}$ are given in Tables 1 and 2. The measured pressures of the different companies' resistors and the calculated models for each flow are presented in Figure 2. As expected, the differences in pressure between the resistors were smaller at a flow of $10 \mathrm{~L} / \mathrm{min}$ compared with $18 \mathrm{~L} / \mathrm{min}$. The pressure differences were also smaller with increasing lumen diameter.

At a standardized flow, resistors from different companies that were reported to have the same diameter produced significantly different pressures (see Tables 1 and 2). Regardless of the flow, there were statistically significant differences between pressures generated by resistors in a size rage of 1.5-4.0 mm (analysis of variance, $P<.001$ ). Results from the post hoc tests revealed that when resistors were compared pairwise, there were statistically significant differences at a flow of $10 \mathrm{~L} / \mathrm{min}$ with 1.5- and 2.0-mm diameter resistors and at a flow of $18 \mathrm{~L} / \mathrm{min}$ with $2.0-\mathrm{mm}$ diameter resistors $(P<.001)$. However, there were no statistically significant differences between any of the 4.5- and 5.0-mm resistors at either flow.

At a constant flow of $10 \mathrm{~L} / \mathrm{min}$, the Mini-PEP gave significantly higher pressures than the Pep/Rmt system when testing the resistors from 1.5 to $3.0 \mathrm{~mm}(P<.001)$. The 15-mm endo-adapter resistor gave significantly higher pressures than the other resistors at all sizes except $5.0 \mathrm{~mm}$ $(P<.05)$. At a flow of $18 \mathrm{~L} / \mathrm{min}$, the Mini-PEP gave significantly higher pressures that the Pep/Rmt system and Pipe $\mathrm{P}$ when comparing resistors from 2.0 to $3.0 \mathrm{~mm}$ $(P>.001)$. The $15-\mathrm{mm}$ endo-adapter resistors with diameters of $2.0-3.5 \mathrm{~mm}$ gave significantly higher pressures compared with the other 3 resistors of each size $(P<.001)$.

Table 1. Measured Pressures Obtained With Different Proprietary Resistor Components of 4 Commercial PEP Devices at a Flow 10 L/min

\begin{tabular}{|c|c|c|c|c|c|c|}
\hline \multirow{2}{*}{$\begin{array}{c}\text { Resistor } \\
\text { Diameter (mm) }\end{array}$} & \multicolumn{4}{|c|}{ Pressure $\left(\mathrm{cm} \mathrm{H}_{2} \mathrm{O}\right)$} & \multirow{2}{*}{$P^{*}$} & \multirow{2}{*}{$\begin{array}{c}\text { Significant Differences } \\
\text { Between: }\end{array}$} \\
\hline & Pep/Rmt System & Pipe P & Mini-PEP & 15-mm Endo-Adapter & & \\
\hline 1.5 & $20 \pm 0$ & $23.7 \pm 1.2$ & $26.5 \pm 0.9$ & & $<.001$ & All $(P<.001)$ \\
\hline 2.0 & $9 \pm 0$ & $11.8 \pm 0.3$ & $13.5 \pm 0$ & $15 \pm 0$ & $<.001$ & All $(P<.001)$ \\
\hline 2.5 & $5.8 \pm 0.3$ & $6 \pm 0$ & $7 \pm 0$ & $8 \pm 0$ & $<.001$ & $\begin{array}{l}\text { Mini-PEP vs all }(P<.001) \\
\text { Endo-adapter vs all }(P<.001)\end{array}$ \\
\hline 3.0 & $3 \pm 0$ & $3 \pm 0$ & $4 \pm 0$ & $5 \pm 0$ & $<.001$ & $\begin{array}{l}\text { Mini-PEP vs all }(P<.001) \\
\text { Endo-adapter vs all }(P<.001)\end{array}$ \\
\hline 3.5 & $2 \pm 0$ & $2 \pm 0$ & $2 \pm 0$ & $3 \pm 0$ & $<.001$ & Endo-adapter vs all $(P<.001)$ \\
\hline 4.0 & $1 \pm 0$ & $1 \pm 0$ & $1 \pm 0$ & $1.5 \pm 0$ & $<.001$ & Endo-adapter vs all $(P<.05)$ \\
\hline 4.5 & $1 \pm 0$ & $1 \pm 0$ & $1 \pm 0$ & & .42 & NS \\
\hline 5.0 & $0.5 \pm 0$ & $0.5 \pm 0$ & $0.8 \pm 0.3$ & $1 \pm 0$ & .36 & NS \\
\hline $\begin{array}{l}\text { Values are mean } \pm \mathrm{SD} \\
* \text { Analysis of variance. } \\
\mathrm{NS}=\text { not significant }\end{array}$ & & & & & & \\
\hline
\end{tabular}


Evaluation of DifFerent PEP Resistors

Table 2. Measured Pressures Obtained With Different Proprietary Resistor Components of 4 Commercial PEP Devices at a Flow of 18 L/min

\begin{tabular}{|c|c|c|c|c|c|c|}
\hline \multirow{2}{*}{$\begin{array}{c}\text { Resistor } \\
\text { Diameter (mm) }\end{array}$} & \multicolumn{4}{|c|}{ Pressure $\left(\mathrm{cm} \mathrm{H}_{2} \mathrm{O}\right)$} & \multirow{2}{*}{$P^{*}$} & \multirow{2}{*}{$\begin{array}{c}\text { Significant Differences } \\
\text { Between: }\end{array}$} \\
\hline & Pep/Rmt System & Pipe P & Mini-PEP & 15-mm Endo-Adapter & & \\
\hline 1.5 & $>70 \pm 0$ & $>70 \pm 0$ & $>70 \pm 0$ & & $<.001$ & NA \\
\hline 2.0 & $32.5 \pm 0.3$ & $42.7 \pm 0.6$ & $47.7 \pm 0.6$ & $51.2 \pm 0.8$ & $<.001$ & All $(P<.001)$ \\
\hline 2.5 & $21 \pm 0$ & $21.2 \pm 0.3$ & $25 \pm 0$ & $28.3 \pm 0.3$ & $<.001$ & $\begin{array}{l}\text { Mini-PEP vs all }(P<.001) \\
\text { Adapter vs all }(\mathrm{p}>.001)\end{array}$ \\
\hline 3.0 & $12 \pm 0$ & $12 \pm 0$ & $14 \pm 0$ & $17.5 \pm 0$ & $<.001$ & $\begin{array}{l}\text { Mini-PEP vs all }(P<.001) \\
\text { Adapter vs all }(P<.001)\end{array}$ \\
\hline 3.5 & $7 \pm 0$ & $8 \pm 0$ & $8 \pm 0$ & $10 \pm 0$ & $<.001$ & $\begin{array}{l}\text { Pep/Rmt system vs all } \\
\text { Adapter vs all }(P<.001)\end{array}$ \\
\hline 4.0 & $5 \pm 0$ & $4 \pm 0$ & $5 \pm 0$ & $5.2 \pm 0.3$ & $<.001$ & Pipe $\mathrm{P}$ vs all $(P<.001)$ \\
\hline 4.5 & $3 \pm 0$ & $2.5 \pm 0.5$ & $3 \pm 0$ & & .10 & NS \\
\hline 5.0 & $2 \pm 0$ & $2.5 \pm 0$ & $2 \pm 0$ & $2 \pm 0$ & .09 & NS \\
\hline $\begin{array}{l}\text { Values are mean } \pm \mathrm{SD} \\
* \text { Analysis of variance. } \\
\mathrm{NA}=\text { not applicable } \\
\mathrm{NS}=\text { not significant }\end{array}$ & & & & & & \\
\hline
\end{tabular}

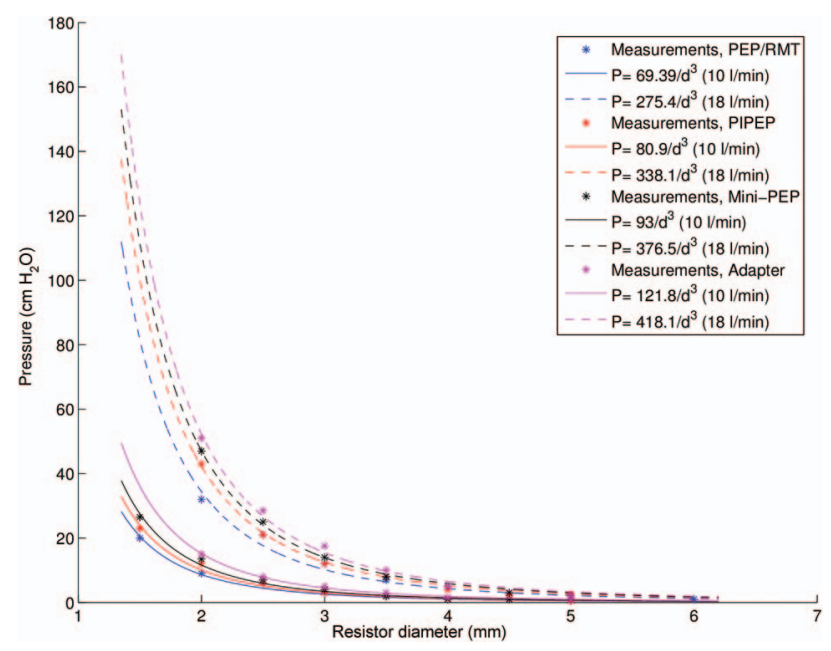

Fig. 2. Graph and calculated model of the pressures $(P)$ from the different resistors according to resistor diameter (d). Solid lines show flow at $10 \mathrm{~L} / \mathrm{min}$, and dashed lines show flow at $18 \mathrm{~L} / \mathrm{min}$.

\section{Discussion}

The main findings of this study are that pressures generated by the resistors from 4 different PEP devices are not comparable, even though the diameter of the resistors is reported to be similar. All resistors differed significantly from each other in measurements of the smallest diameters, and the differences were smaller at lower flows. In addition, the resistor from the 15 - $\mathrm{mm}$ endo-adapter gave significantly higher pressures than the other resistors up to $3.5 \mathrm{~mm}$.

The pressure achieved in a PEP system is based on the flow through the system and the resistance. Our main finding is that, even if the diameters are reported to be the same, the pressures exerted by resistors from various companies differ, which was most prominent when testing resistances with smaller diameters at higher flows. At a lower flow with a larger lumen, the differences between the resistors were not large enough to be detected under our experimental conditions. A relevant question is whether different resistors with the same diameter are interchangeable in clinical practice. Different companies manufacture resistors that are also adaptable to other PEP systems. In addition, some companies use the same color code for the resistors: the $3.5-\mathrm{mm}$ resistors from the Pep/Rmt system, Pipe $\mathrm{P}$, and $15-\mathrm{mm}$ endo-adapter are all green. For this reason, resistors from different PEP devices may be mixed up in a ward.

Although the resistors that were tested look similar at first glance, there are visible differences, especially on the inside (see Fig. 1). The resistors from the $15-\mathrm{mm}$ endoadapter have a longer tube with a tapered end. The other resistors (the Pep/Rmt system, Pipe P, and Mini-PEP) have a similar design, but the pressure measured is higher with the Mini-PEP resistors and lower with the Pep/Rmt system. The differences in design, including the length and shape of the tube, are reasons for the statistically different pressures measured during the tests. Pressure in cylindrical pipes at a laminar flow can be calculated by the Poiseuille equation. Estimated pressure was calculable for 3 of the resistor brands because they are cylindrical. According to calculations, they should have the same pressure; however, this was not borne out by our experimental results, and we observed significant differences. We postulate that this is probably due to lack of accuracy regarding lumen size and the different tube lengths. The exception in these calculations of estimated pressure is the resistors from the 
15-mm endo-adapter. The diameter of these resistors differs along the length of the tube, as they are tapered, and it is harder to estimate pressure. In addition, the relationship between laminar and turbulent flow also affects pressure. The ideal pressure expected for each resistor is therefore not possible to determine. Nevertheless, our main finding is that the resistors give different pressures, even if the diameter is said to be the same. Although the lumens of the resistors are similar in cross-sectional area, other geometrical aspects of the resistors' designs result in significantly different pressures.

Resistance during flow is generated not only by the resistors themselves, but also by the valve used in PEP. ${ }^{8}$ In a previous study, the Pep/Rmt valve gave the highest resistance, and the pressure measured at constant flows showed a mean of $2.6 \mathrm{~cm} \mathrm{H}_{2} \mathrm{O}$, whereas System 22 had a mean pressure of $0.5 \mathrm{~cm} \mathrm{H}_{2} \mathrm{O}$, and the Pari PEP had a mean pressure of $0.9 \mathrm{~cm} \mathrm{H}_{2} \mathrm{O} .{ }^{8}$ Differences in pressure have been described when the blow bottle was tested, where the water column combined with the diameter and length of the tube determines the level of pressure. ${ }^{7}$ There is also a difference in pressure when a mask or mouthpiece is used. ${ }^{9}$ When using PEP, it is important to be aware that the pressure achieved is dependent on the equipment, as valves and resistors and changing between different devices and systems affect the pressure.

The decision to use flows of 10 and $18 \mathrm{~L} / \mathrm{min}$ was based on studies evaluating PEP in subjects with COPD that showed a flow of $8-12 \mathrm{~L} / \mathrm{min}^{10-12}$ and healthy subjects with reported flows of $18 \mathrm{~L} / \mathrm{min}^{13,14}$ when breathing through a PEP device. As expected, the differences between resistors of the same diameter increase with an increased flow, and according to the equations shown in Figure 2, the differences will be more significant at higher flows. The clinical application of our results is that mixing resistors from different companies has an even larger impact on patients who breathe at high flows.

Adverse effects of PEP treatment are seldom reported in clinical trials. In a review evaluating evidence on PEP training for subjects with COPD, only 3 of 11 articles registered adverse effects. ${ }^{2}$ Reported effects were complaints about the mask, dizziness caused by hyperventilation, and the treatment in general. The risk of adverse effects is minor, but it is a challenge to prescribe the optimal treatment.

The immediate effect of PEP on lung volume is dependent on several components. The pressure produced and the breathing pattern, including expiratory force and expired volume, are important in achieving effective treatment. ${ }^{15}$ Although known clinically, the significant differences between the resistors tested in this study had not been reported previously. It is hard to prove these differences in clinical settings because treatment depends on so many factors. However, these differences are worth ex- ploring when prescribing PEP treatment to patients, especially when using small-sized resistors and with patients who breathe at a high flow.

Considering our results, it would be unwise to exchange resistors from different companies if it is important for a patient to receive a certain and precise pressure. Even though breathing pattern is the most important factor for regulating pressure, and most of the differences in pressure between the resistors tested in this study are minor, changes in pressure can still be clinically relevant, particularly when considering frail patients who cannot communicate effectively or who are sensitive to high pressures due to respiratory failure or muscular fatigue. ${ }^{16} \mathrm{~A}$ change in resistance and pressure could result in such patients carrying out the treatment in a manner that is suboptimal.

A limitation of the study is that it was not carried out with subjects, as their air flow fluctuates as part of normal respiration. However, the flow was standardized using an external gas system, and this was important to be able to accurately measure differences between resistors. Another limitation is that the choice of the 4 PEP devices tested was arbitrary. They were selected because they are available and are used in clinical practice in Sweden, where the study was carried out. However, we chose to evaluate resistors from systems with PEP devices that share a similar structure and design to be able to focus on the actual differences between the resistors. It is important to further test and compare other kinds of PEP devices and resistors in clinical settings to better understand their differences.

\section{Conclusions}

Pressures generated by the different proprietary resistor components of 4 commercial PEP devices were not comparable, even though the diameter of the resistors is reported to be the same. The pressures generated were significantly different, particularly when using small-diameter resistors at a high flow. Therefore, the resistors may not be interchangeable. This is important for clinicians, particularly when considering PEP for patients who do not tolerate higher pressures.

\section{REFERENCES}

1. Elkins MR, Jones A, van der Schans C. Positive expiratory pressure physiotherapy for airway clearance in people with cystic fibrosis. Cochrane Database Syst Rev 2006;19;(2):CD003147.

2. Fagevik Olsén M, Westerdahl E. Positive expiratory pressure for patients with chronic obstructive pulmonary disease-a systematic review. Respiration 2009;77(1):110-118.

3. Orman J, Westerdahl E. Chest physiotherapy with positive expiratory pressure breathing after abdominal and thoracic surgery: a systematic review. Acta Anaesthesiol Scand 2010;54(3):261-267.

4. Breslin EH. The pattern of respiratory muscle recruitment during pursed-lips breathing. Chest 1992;101(1):75-78. 


\section{Evaluation of Different PEP Resistors}

5. Ingram RH Jr, Schilder DP. Effect of pursed lips expiration in the pulmonary pressure-flow relationship in obstructive lung disease. Am Rev Respir Dis 196(3)7;96:381-388.

6. van der Shans CP, de Jong W, Kort E, Wijkstra PJ, Koeter GH, Postma DS, van der Mark TW. Mouth pressure during pursed lips breathing. Physiother Theory Pract 1995;11(1):29-34.

7. Mestriner RG, Fernandes RO, Steffen LC, Donadio MV. Optimum design parameters for a therapist-constructed positive-expiratorypressure therapy bottle device. Respir Care 2009;54(4):504-508.

8. Christensen EF, Jensen RH, Schønemann NK, Petersen KD. Flowdependent properties of positive expiratory pressure devices. Monaldi Arch Chest Dis 1995;50(2):150-153.

9. Clase Larsson S, Fagevik Olsén M. An evaluation of positive expiratory pressure using mask and mouthpiece. Adv Physiother 2006; 8(3):116-121.

10. Bianchi R, Gigliotti F, Romagnoli I, Lanini B, Castellani C, Grazzini M, Scano G. Chest wall kinematics and breathlessness during pursedlips breathing in patients with COPD. Chest 2004;125(2):459-465.
11. Bianchi R, Gigliotti F, Romagnoli I, Lanini B, Castellani C, Binazzi $\mathrm{B}$, et al. Patterns of chest wall kinematics during volitional pursed-lip breathing in COPD at rest. Respir Med 2007;101(7):1412-1418.

12. Mueller RE, Petty TL, Filley GF. Ventilation and arterial blood gas changes induced by pursed lips breathing. J Appl Physiol 1970; 28(6):784-789.

13. Fagevik Olsén M, Lönroth H, Bake B. Effects of breathing exercises on breathing patterns in obese and normal subjects. Clin Physiol 1999;19(3):251-257.

14. Sehlin M, Ohberg F, Johansson G, Winsö O. Physiological responses to positive expiratory pressure breathing: a comparison of the PEP bottle and the PEP mask. Respir Care 2007;52(8):1000-1005.

15. Fagevik Olsén M, Lannefors L, Westerdahl E. Positive expiratory pressure-common clinical applications and physiological effects. Respir Med 2015;109(3):297-307.

16. Lagerkvist AL, Sten G, Westerberg B, Ericsson-Sagsjö A, Bjure J. Positive expiratory pressure (PEP) treatment in children with multiple severe disabilities. Acta Paediatr 2005;94(5):538-542. 